\title{
Prevalence and Risk Factors of HCV/HIV Co-Infection and HCV Genotype Distribution in North-Eastern Poland
}

\author{
Anna Grzeszczuk ${ }^{1, *} ;$ Alicja Danuta Wandalowicz ${ }^{1}$; Jerzy Jaroszewicz ${ }^{1}$; Robert Flisiak ${ }^{1}$ \\ ${ }^{1}$ Department of Infectious Diseases and Hepatology, Medical University of Bialystok, Bialystok, Poland \\ ${ }^{*}$ Corresponding Author: Anna Grzeszczuk, Department of Infectious Diseases and Hepatology, Medical University of Bialystok, Zurawia 14 St., 15-540 Białystok, Poland. Tel/Fax: \\ +48-857416921, E-mail: oliwa@umb.edu.pl
}

Received: February 6, 2015; Revised: March 5, 2015; Accepted: April 25, 2015

\begin{abstract}
Background: HIV/HCV co-infection predisposes to accelerated liver damage and increased both liver-related and unrelated morbidity and mortality in patients with HIV infection.

Objectives: The aim of this study was to evaluate the prevalence of HCV infection, seropositivity, risk factors and genotype distribution among treated HIV positive patients. Furthermore, the occurrence and causes of deaths were analyzed.

Patients and Methods: Adult HIV-1 infected patients, with at least one antiHCV result, treated in one of Polish HIV/AIDS reference centers, participated in this cross-sectional study.

Results: Four hundred and fifty seven patients with a median age of 38 years (ranged 23-72), and predominantly male (76.6\%) were enrolled in the study. Anti-HCV antibodies were detected in 325 individuals (71.1\%). HCV RNA was detected in 207 of the 233 patients tested (88\%). The HCV genotype analysis ( $n=193$ ) demonstrated almost equal distribution with slight genotype 1 domination as $37.3 \%$, mainly $1 b$, followed by genotypes 3 as $32.1 \%$ and 4 as 30.6\%. No association was found between HCV genotype and route of HIV acquisition. In univariate analysis, higher HCV seropositivity was related to male sex, intravenous drug use (IDU), mode of HIV transmission, history of drug and alcohol abuse and imprisonment. In multivariate analysis, only being injection drug user $(\mathrm{P}=0.0001)$, imprisonment $(\mathrm{P}=0.310)$ and younger age at the HIV diagnosis per each year $(\mathrm{P}=0.025)$ were identified as risk factors for HCV infection. Sixty three deaths were reported; no association was found between HCV seropositivity and death prevalence.

Conclusions: HIV/HCV co-infection is an important medical problem in North-Eastern Poland. A history of incarceration and younger age at HIV diagnosis were additional to IDU risk factors for HCV seropositivity in this cohort.
\end{abstract}

Keywords: Human Immunodeficiency Virus; Hepatitis C Virus; Prevalence; Genotypes; Poland

\section{Background}

Highly active antiretroviral treatment (HAART) has resulted in a shift in the causes of morbidity and mortality to non-HIV related causes $(1,2)$. Liver disease is now a leading cause of death in patients with HIV (PLHIV, people living with HIV), mainly due to chronic hepatitis $\mathrm{C}(2-4)$. The prevalence and incidence of both human immunodeficiency virus (HIV) and Hepatitis C virus (HCV) have increased in Poland in the recent years (5-10). There were 18646 officially registered HIV cases between 1985 and 31st December 2014 (11). HCV infection incidence was 5.58 per 100,000 in 2011, with a marked increase in deaths reported in 2011 (9). Shared transmission routes are responsible for the high rate of co-infection, increasing both the complexity of disease management and the public health burden (3).

The prevalence of HIV/HCV coinfection varies greatly across the world, from as low as $0.9 \%$ in Istambul, Turkey up to above $90 \%$ in Russia, Bielarus, Ukraine, Latvia, Estonia (12, 13). Polish data regarding HIV/HCV coinfection prevalence and genotype distribution are scarce and fragmentary (1417). No studies are available regarding the risk factors of HCV infection among people living with HIV (PLHIV).

\section{Objectives}

The aim of this study was to analyze the prevalence of HCV infection based on anti-HCV serology and HCV-RNA and HCV genotype distribution in a group of PLHIV from one of the Polish HIV/AIDS reference centers located in north-eastern Poland. Risk factors associated with HCV infection and causes of death in our cohort were also studied.

\section{Patients and Methods}

Study participants were recruited from adult, HIV-1 infected patients, treated in HIV/AIDS outpatient clinic of medical university teaching hospital in Bialystok, north-eastern Poland, (Table 1) one of 17 HIV/AIDS reference centers in the country. A total of 836 patients were eligible for the study and 457 were enrolled. The main inclusion criterion was at least one anti-HCV test result available. No exclusion criteria were applied. Prospective data collection was started from 2008 for all patients on initial attendance and retrospectively for those who had their first visit prior to 2008 and was conducted until the end of December 2013. The collected

Copyright (C) 2015, Kowsar Corp. This is an open-access article distributed under the terms of the Creative Commons Attribution-NonCommercial 4.0 International License (http://creativecommons.org/licenses/by-nc/4.0/) which permits copy and redistribute the material just in noncommercial usages, provided the original work is properly cited. 
clinical and epidemiological parameters included age, gender, ethnicity, duration of HIV infection, mode of HIV transmission [sexual: hetero- or homosexual, injecting drug use (IDU), mixed-sexual and IDU or unknown], history of incarceration, mental disorders and alcohol abuse, HBs seropositivity, date and cause of death. All patients were Caucasian. No data regarding the length and numbers of incarcerations were analyzed. The nadir CD4 T lymphocyte count, measured by flow cytometry, was collected. The study was approved by Medical University of Bialystok ethical committee.

\subsection{Serological Analysis}

Anti-HCV antibodies and HBs antigen were measured at the baseline evaluation of all HIV positive individuals with commercial serological assays (Architect, Abbott).

\subsection{Molecular Tests}

HCV-RNA was analyzed using RT PCR. Cobas Ampli Prep and Cobas Taqman (Roche Diagnostics) were used with lowest detection limit of $11 \mathrm{IU} / \mathrm{mL}$. HCV genotypes were determined using Versant HCV (Bayer Diagn, Germany).

\subsection{Deaths Analysis}

The analysis of deaths was based on clinical and autopsy data, where available. Information for patients who died in our center is complete. Where patients died at home or at other medical institutions, their family was contacted and asked to provide all the available data regarding patient's death.

\subsection{Statistical Methods}

The data was analyzed with Statistica PL software (Statsoft, USA), using Mann-Whitney, Fisher and chi ${ }^{2}$ tests. In the multivariate model, the following factors were included; age at first positive HIV Western Blot, heterosexual route of HIV transmission, HBs seropositivity, history of incarceration, injecting drug use, alcohol misuse and psychiatric disorders.

\section{Results}

Four hundred and fifty seven adult patients with HIV infection attending for treatment and care at the outpatient clinic, medical university teaching hospital, Bialystok, north-eastern Poland were included. The median age was 38 years (ranged 23 - 72 years); most were male, 350/457 (76.6\%) Table 1. Most patients acquired HIV infection via intravenous drug use, 264/457 (57.8 \%). Anti-HCV antibodies were detected in 325 (71.1\%), who were significantly younger with a median age of 37 years [ranged 23 - 57] compared to anti-HCV negative patients; median age 41.0 years [ranged $23-72$ ], $\mathrm{P}=0.04$ (Table 1); positivity varied across age groups (Table 2 ). Univariable analysis revealed that male sex, younger age at HIV diagnosis and at the study time, injecting drug use as route of HIV transmission, alcohol misuse and a history of imprisonment were all factors associated with anti-HCV seroprevalence (Table 2). The history of psychiatric disease was not associated with a higher risk of HCV seropositivity ( $\mathrm{P}=$ 0.07589). In multivariable analysis only;

- Being injection drug user [OD 125.02; 95\% CI 10.761453.62; $\mathrm{P}=0.0001]$,

- History of imprisonment [OD 4.454; 95\% CI 1.141-17.394; $\mathrm{P}=0.310]$ and

- Younger age at the HIV diagnosis [OD 0.857; 95\% CI $0.749-0.981 ; \mathrm{P}=0.025]$ were identified as risk factors for $\mathrm{HCV}$ infection.

\subsection{Time Trends in HCV Infection}

We analyzed the prevalence of HCV infection in two groups of PLHIV: those diagnosed before 2005 and those diagnosed during or after 2005. There was a significant decrease in HCV seroprevalence from $85.2 \%$ (218/256) to $53.2 \%(107 / 201)$ in the whole group analyzed $(\mathrm{P}=0.0001)$. However, differences among patients who acquired HIV via different routes of exposure were not significant. Trends of decrease were observed in IDUs and IDUs/heterosexualy infected. HCV seroprevalence increased in MSM (men who have sex with men) and unknown way of HIV transmission, Table 3.

\begin{tabular}{|c|c|c|c|c|}
\hline Variables & Study Group & HIV/HCV Coinfection & HIV Monoinfection & PValue \\
\hline Number of patients & 457 & $325(71.1)$ & $132(29.9)$ & \\
\hline Age, $y$ & $38.0(23-72)$ & $37.0(23-57)$ & $41.0(23-72)$ & 0.04 \\
\hline Gender, male & $350(76.6)$ & $264(81.2)$ & $86(65.1)$ & 0.0002 \\
\hline Age at HIV diagnosis, y & $29.1(14-64)$ & $26.0(14-51)$ & $33.5(17-64)$ & $<0.0001$ \\
\hline Length of HIV infection, $y$ & $10(0-26)$ & $11.3(1-26)$ & $7.0(0-21)$ & $<0.0001$ \\
\hline Nadir CD4, cells $/ \mu \mathrm{L}$ & $199(4-1176)$ & $199(4-1174)$ & $199.5(4-886)$ & 0.2826 \\
\hline
\end{tabular}

\footnotetext{
a Data are presented as No.(\%) or median (range).
} 
Grzeszczuk A et al.

Table 2. Prevalence, Co-Morbidities and Univariate Analysis of Risk Factors for Anti-HCV Seropositivity Among HIV Infected Individuals, North-Eastern Poland ${ }^{a}$

\begin{tabular}{|c|c|c|c|c|}
\hline Variables & Study Group Total & HIV/HCV co-Infection & HIV Monoinfection & P Value \\
\hline Age groups at HIV Western Blot, y & & & & $<0.0001$ \\
\hline$<20$ & 52 & $7(13.5)$ & $45(86.5)$ & \\
\hline $20-29$ & 224 & $178(79.5)$ & $46(20.5)$ & \\
\hline $30-39$ & 127 & $87(68.5)$ & $40(31.5)$ & \\
\hline$\geq 40$ & 54 & $39(72.2)$ & $15(13.5)$ & \\
\hline Current age groups, $y$ & & & & $<0.0001$ \\
\hline$<30$ & 41 & $20(48.9)$ & $21(51.2)$ & \\
\hline $30-39$ & 210 & $170(81.0)$ & $40(19.1)$ & \\
\hline $40-49$ & 154 & $116(75.3)$ & $38(24.7)$ & \\
\hline$\geq 50$ & 52 & $19(36.9)$ & $33(63.5)$ & \\
\hline Gender & & & & 0.0002 \\
\hline Male & $350(76.6)$ & $264(81.2)$ & $86(65.1)$ & \\
\hline Female & $107(23.4)$ & $61(18.8)$ & $64(34.8)$ & \\
\hline HIV transmission & & & & $<0.0001$ \\
\hline IDU & 264 & $258(97.7)$ & $6(2.3)$ & \\
\hline Sexual & 151 & $31(20.5)$ & $120(79.5)$ & \\
\hline \multicolumn{5}{|l|}{ HIV transmission detailed } \\
\hline IDU & 264 & $258(97.7)$ & $6(2.3)$ & \\
\hline Heterosexual & 111 & $28(25.3)$ & $83(62.9)$ & \\
\hline Homosexual & 40 & $3(7.5)$ & $37(28.0)$ & \\
\hline IDU/heterosexual & 21 & $20(95.2)$ & $1(4.8)$ & $<0.0001$ \\
\hline Unknown & 21 & $16(76.2)$ & $5(23.8)$ & \\
\hline \multicolumn{5}{|l|}{ Imprisonment } \\
\hline Yes & 107 & $100(93.5)$ & $7(6.5)$ & \\
\hline No & 345 & $222(64.4)$ & $123(35.7)$ & $<0.0001$ \\
\hline \multicolumn{5}{|l|}{ Alcohol abuse } \\
\hline Yes & 62 & $52(83.9)$ & $10(16.1)$ & \\
\hline No & 389 & $269(62.2)$ & $120(30.8)$ & 0.01748 \\
\hline \multicolumn{5}{|l|}{ Psychiatric disease } \\
\hline Yes & 34 & $25(73.5)$ & $9(26.5)$ & \\
\hline No & 418 & $297(71.1)$ & $121(29)$ & 0.07589 \\
\hline
\end{tabular}

Table 3. HCV Seropositivity Among PLHIV Diagnosed Before the Year 2005 or in the Year 2005 and Later ${ }^{\text {a }}$

\begin{tabular}{lccc}
\hline HIV Mode of Transmission & \multicolumn{2}{c}{ Number of Anti-HCV, Positive/Total Number (\%) } & \multirow{2}{*}{ PValue $^{\mathrm{b}}$} \\
\cline { 2 - 3 } & HIV WB Before Year 2005 & HIV WB Year 2005 and Later & 0.0676 \\
\hline IDU & $183 / 185(98.9)$ & $75 / 79(94.9)$ & 0.2914 \\
Heterosexual & $11 / 37(29.7)$ & $17 / 74(23.0)$ & 0,6057 \\
Homosexual (MSM) & $0 / 6(0)$ & $3 / 34(2.8)$ & 0,2219 \\
IDU/heterosexual & $12 / 13(92.3)$ & $4 / 6(66.7)$ & 0,2567 \\
Unknown & $12 / 15(80.0)$ & $8 / 8(100)$ & $<0.0001$ \\
\hline
\end{tabular}

a Abbreviation: PLHIV, people living with HIV.
b Fisher exact test. 


\subsection{HCV-RNA Detection and HCV Genotypes Analysis}

HCV-RNA and/or genotyping was performed in 233 patients being potential candidates for treatment; HCV RNA was detected in 207 (88\%). Among 13 patients seronegative for HCV tested for HCV RNA and/or HCV genotype, only two had positive HCV-RNA results (occult HCV infection). The genotype results were available for 193 patients. Regarding the HCV genotype (GT) distribution, our analysis showed almost equal GT1, GT3 and GT4 distribution, with slight GT1 domination, which was found in 72 persons (37.3\%), mainly GT1b, followed by GT3 detected in 62 PLHIV (32.1\%) and GT4 in 59 PLHIV (30.6\%). No significant differences in HCV genotypes distribution were found between patients who had different HIV acquisition routes.

\subsection{Deaths}

Sixty three deaths were registered in the study group, 17 among HCV seronegative patients and 46 in seropositive ones, $\mathrm{P}=0.773$. In 13 cases, the cause of death was unknown. Further analysis of the causes of death, including comparing liver-related versus other causes showed no significant differences between HCV seropositive and seronegative individuals, $\mathrm{P}=0.390$.

\section{Discussion}

Four hundred and fifty seven patients, with a median age of 38 years [range $23-72$ ], predominantly males, $76.6 \%$ were studied. Anti-HCV antibodies were detected in most, 325/457 (71.1\%). The highest seroprevalence was found in the 30 - 40 year old group as $81 \%$. Our study group can be considered as an example of an "old" HIV cohort with IDU as the predominant means of HIV acquisition, 264/457 (57.8\%). However, the proportion of MSM among new HIV diagnoses increases each year, both in our center and the country as a whole, Table 3 (18). The $71.1 \%$ anti-HCV seropositivity detected in our cohort is very high. The EuroSIDA cohort study reported an average 33\% HCV seropositivity across Europe with sig- nificant regional variations (13). The highest prevalence was detected in eastern and southern Europe, where co-infection rates were about 50\%. The highest and less variable seroprevalence was seen among IDUs from all participating countries, reaching 70 - 100\% (Table 4). A recent Turkish study confirmed that HCV seropositivity was strongly related to IDU (12). This observation is in line with our analysis, which revealed IDU as a risk factor for HCV seropositivity.

Since 2000 the sexual transmission of HCV between MSM has been of increasing concern (20-22). Epidemics of acute hepatitis $C$ infections and multiple re-infections have been reported (20-23). We did not diagnose any acute hepatitis $C$ among the study patients; however, the study design was cross-sectional and HCV incidence data is not available. Cases of acute hepatitis C in HIV positive MSM have recently been found in Warsaw, the capital and Krakow [unpublished, personal communications -Dr. E. Firląg-Burkacka, Dr. M. Bociaga-Jasik].

A recent analysis of $14651 \mathrm{HCV}$ genotypes in the general population in Poland between 2003 - 2012 revealed a predominance of GT1 as $79.4 \%$, followed by GT3 as $13.8 \%$ and GT4 as $4.9 \%$ (14). Locally in north-eastern Poland, the proportion of GT3 and GT4 were significantly higher as $23 \%$ and $8.6 \%$, respectively (14). However, the proportions of GT3 and GT4 were even higher in earlier analysis, conducted between 2002 and 2006, reaching 34.1\% and 15.5\%, respectively $(15,24)$. HCV G3 was the major genotype seen among Polish prisoners (16). International EuroSIDA analysis, comprising eastern European countries, including Poland also reported higher proportions of HCV GT3 as $40 \%$, GT $419 \%$ and GT1 as $40 \%$ (25). The percentage of patients with replicating HCV in our study was higher than that seen in the EuroSIDA survey as $88.8 \%$ versus $77 \%$ (25).

Our study identified a history of imprisonment as an independent risk factor for HCV infection among PLHIV, consistent with an earlier study of IDUs in the community (26). The dynamics of blood borne infections, HBV, HCV and HIV, the history of illicit drug use and imprisonment are closely intertwined. Several European studies

\begin{tabular}{|c|c|c|c|c|c|}
\hline \multirow[t]{2}{*}{ Country } & \multicolumn{2}{|c|}{ Patients of Known HCV Serostatus } & \multicolumn{2}{|c|}{ IDUs of Known HCV Serostatus } & \multirow{2}{*}{$\begin{array}{l}\text { HCV-Seropositive Patients Who } \\
\text { Acquired HIV via Injection Drug use, \% }\end{array}$} \\
\hline & Total, No. & HCV Seropositive, \% & Total No. & HCV Seropositive, \% & \\
\hline Poland ${ }^{\mathrm{b}}$ & 484 & 61.2 & 255 & 96.1 & 82.8 \\
\hline Belarus ${ }^{b}$ & 47 & 70.2 & 31 & 96.8 & 90.9 \\
\hline Lithuania $^{b}$ & 80 & 51.3 & 39 & 94.9 & 90.2 \\
\hline Russia $^{b}$ & 93 & 25.8 & 17 & 100.0 & 70.8 \\
\hline Ukraine $^{\text {b }}$ & 122 & 71.3 & 82 & 97.6 & 92.0 \\
\hline Latvia ${ }^{b}$ & 93 & 66.7 & 64 & 87.5 & 90.3 \\
\hline Estonia ${ }^{b}$ & 80 & 56.3 & 38 & 94.7 & 80.0 \\
\hline Moldova & 448 & 50.7 & - & - & - \\
\hline
\end{tabular}

a Abbreviation: IDU, injection drug user

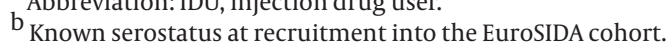


reported higher HIV and HCV prevalence and incidence in prisons (26-30). Polish data are summarized in Table 4. A cross-sectional study in French prison inmates showed 2.9\% HIV and $4.8 \%$ HCV prevalence, which was six times higher than the general population, with $2.5 \%$ of inmates having viremic hepatitis C (27). In Spain, among 2377 prisoners, $117 \mathrm{HCV}$ seroconversions were detected, giving an incidence of 1.17/100 patient/years $(29,30)$. The incidence was higher among cases with HIV co-infection (8.34/100 patient/years (py)) and IDUs without methadone replacement treatment during follow-up (6.66/100 py) (29). All potential routes of HCV transmission can occur in prison such as sharing of contaminated injection equipment, unsafe sexual contacts, unsafe skin penetrations (piercing, tattooing, sharing razors and blood-sharing rituals); however, this period of obligatory isolation may provide conditions for optimal adherence during chronic hepatitis $C$ treatment.

Recent studies indicated that the prevalence and total number of patients with anti-HCV has increased from 2.3\% (95\% uncertainty interval [UI]: $2.1 \%$ - $2.5 \%$ ) to $2.8 \%$ (95\% UI: $2.6 \%-3.1 \%)$ and from more than 122 million to more than 185 million between 1990 and 2005 (31, 32). In the general population in Poland, HCV antibodies were detected in $1.9 \%$ of over 26000 adults; HCV-RNA was detectable in $31 \%$ of seropositive individuals (33).

Our study results showed a decrease in HCV prevalence in HIV infected individuals from $85.2 \%$ to $53.2 \%$ in those diagnosed before 2005 compared to those diagnosed in 2005 or later. This is in line with other European observations $(17,34,35)$. In the Swiss HIV cohort, HCV incidence has decreased among IDUs, remained stable amongst heterosexuals and increased 18 fold in MSM between 1998 and 2011. In MSM, a history of inconsistent condom use and a history of syphilis predicted HCV seroconversion (33). Similar observations were made in the French national survey, demonstrating a decrease in the overall prevalence of HIV-HCV co-infection from $22-24 \%$ to 16 $18 \%$. This prevalence decreased from $93 \%$ to $87 \%$ among injecting drug users, while it increased from $4 \%$ to $6 \%$ among MSM during 2003 - 2012 (34).

We did not observe any difference of mortality rate between HCV seropositive and seronegative patients. However, the total number of deaths recorded was 63 and in 13 the cause of death was not determined. Data shows that HCV serostatus does not affect HIV1 disease progression; however, liver related deaths are more frequent among co-infected patients $(13,36)$. Besides the accelerated progression of liver damage caused by HCV replication in HIV infected individuals, HCV increases liver-related mortality and risk of renal insufficiency in HIV infected individuals $(19,37,38)$.

Study limitations include its cross-sectional design and single center data analysis. However, our results complement the scarce information currently reported on the Eastern Europe HIV/HCV epidemics. In conclusion, HIV/ $\mathrm{HCV}$ co-infection is an important medical problem in
North-Eastern Poland, requiring relevant attention and curative and preventive measures.

\section{Acknowledgements}

The authors would like to thank Professor Amanda Mocroft for her advice in statistical analysis and Dr. Ann Sullivan for English proof reading.

\section{Authors' Contributions}

Study concept and design: Anna Grzeszczuk; acquisition of data: Anna Grzeszczuk, Alicja Danuta Wandaowicz; analysis and interpretation of data: Jerzy Jaroszewicz, Anna Grzeszczuk, Alicja Danuta Wandaowicz; drafting of the manuscript: Anna Grzeszczuk, Jerzy Jaroszewicz, Robert Flisiak, Alicja Danuta Wandaowicz; critical revision of the manuscript for important intellectual content: Anna Grzeszczuk, Jerzy Jaroszewicz, Robert Flisiak; statistical analysis: Jerzy Jaroszewicz, Anna Grzeszczuk; the study supervision: Anna Grzeszczuk, Robert Flisiak.

\section{Funding/Support}

This work was financially supported by Medical University of Bialystok grant number 132-56918L.

\section{References}

1. Weber R, Ruppik M, Rickenbach M, Spoerri A, Furrer H, Battegay $\mathrm{M}$, et al. Decreasing mortality and changing patterns of causes of death in the Swiss HIV Cohort Study. HIV Med. 2013;14(4):195-207.

2. van der Helm J, Geskus R, Sabin C, Meyer L, Del Amo J, Chene G, et al. Effect of HCV infection on cause-specific mortality after HIV seroconversion, before and after 1997. Gastroenterology. 2013;144(4):751-760 e2.

3. Rockstroh JK, Peters L, Grint D, Soriano V, Reiss P, Monforte A, et al. Does hepatitis $C$ viremia or genotype predict the risk of mortality in individuals co-infected with HIV? J Hepatol. 2013;59(2):213-20.

4. Weber R, Sabin CA, Friis-Moller N, Reiss P, El-Sadr WM, Kirk $\mathrm{O}$, et al. Liver-related deaths in persons infected with the human immunodeficiency virus: the D:A:D study. Arch Intern Med. 2006;166(15):1632-41.

5. Niedzwiedzka-Stadnik M, Rosinska M. [HIV and AIDS in Poland in 2010]. Przegl Epidemiol. 2012;66(2):315-23.

6. Niedzwiedzka-Stadnik M, Rosinska M. HIV and AIDS in Poland in 2011. Przegl Epidemiol. 2013;67(2):267-72.

7. Rosinska M,Zielinski A. Recent increase in HIV rate by age, cohort, period analysis of surveillance data suggests changes in HIV epidemiology in Poland. Cent Eur J Public Health. 2011;19(3):123-7.

8. Rosinska M, Radziszewski F, Stepien M. [Hepatitis C in Poland in 2010]. Przegl Epidemiol. 2012;66(2):287-92.

9. Rosinska M, Parda N, Stepien M. Hepatitis C in Poland in 2011. Przegl Epidemiol. 2013;67(2):247-51.

10. Cornberg M, Razavi HA, Alberti A, Bernasconi E, Buti M, Cooper $\mathrm{C}$, et al. A systematic review of hepatitis $\mathrm{C}$ virus epidemiology in Europe, Canada and Israel. Liver Int. 2011;31 Suppl 2:30-60.

11. HIV infections in Poland. Epidemiological reports.. Available from: http://www.pzh.gov.pl/page.

12. Aydin OA, Yemisen M, Karaosmanoglu HK, Sargin F, Gunduz A, Ceylan B, et al. Low Prevalence of Hepatitis C Virus Infection Among HIV-Positive Patients: Data From a Large-Scale Cohort Study in Istanbul, Turkey. Hepat Mon. 2014;14(8):e18128.

13. Rockstroh JK, Mocroft A, Soriano V, Tural C, Losso MH, Horban A, et al. Influence of hepatitis $C$ virus infection on HIV-1 disease progression and response to highly active antiretroviral therapy. $J$ Infect Dis. 2005;192(6):992-1002.

14. Panasiuk A, Flisiak R, Mozer-Lisewska I, Adamek A, Tyczyno M, 
Halota W, et al. Distribution of HCV genotypes in Poland. Przegl Epidemiol. 2013;67(1):11-6.

15. Chlabicz S, Flisiak R, Lapinski TW, Kowalczuk O, WiercinskaDrapalo A, Pytel-Krolczuk B, et al. Epidemiological features of patients infected with HCV genotype 4 in Poland: Epidemiology of HCV genotype 4 in Poland. Hepat Mon. 2011;11(3):191-4.

16. Tyczyno M, Halota W, Nowak W, Pawlowska M. Distribution of HCV genotypes in the populations of inmates in polish prison potulice and patients hospitalised in bydgoszcz. Hepat Mon 2014;14(5):e14559.

17. Grabczewska, E. , Pawłowska, M. , Halota, W. . Epidemiological aspects of HCV/HIV co-infections. HIV AIDS Rev. 2003;2/3(4):123-6.

18. Niedzwiedzka-Stadnik M, Pielacha M, Rosinska M. HIV and AIDS in Poland in 2012. Przegl Epidemiol. 2014;68(2):283-9.

19. Peters L, Grint D, Lundgren JD, Rockstroh JK, Soriano V, Reiss P, et al. Hepatitis $C$ virus viremia increases the incidence of chronic kidney disease in HIV-infected patients. AIDS. 2012;26(15):1917-26.

20. Urbanus AT, Van De Laar TJ, Geskus R, Vanhommerig JW, Van Rooijen MS, Schinkel J, et al. Trends in hepatitis C virus infections among MSM attending a sexually transmitted infection clinic; 1995-2010. AIDS. 2014;28(5):781-90.

21. Orsetti E, Staffolani S, Gesuita R, De Iaco G, Marchionni E, Brescini $\mathrm{L}$, et al. Changing characteristics and risk factors of patients with and without incident HCV infection among HIV-infected individuals. Infection. 2013;41(5):987-90.

22. van de Laar T, Pybus O, Bruisten S, Brown D, Nelson M, Bhagani S, et al. Evidence of a large, international network of HCV transmission in HIV-positive men who have sex with men. Gastroenteroogy. 2009;136(5):1609-17.

23. Ishikane M, Watanabe K, Tsukada K, Nozaki Y, Yanase M, Igari T, et al. Acute hepatitis C in HIV-1 infected Japanese Cohort: single center retrospective cohort study. PLoS One. 2014;9(6):e100517.

24. Chlabicz S, Bonifatiuk I, Radziwon P. Prevalence of hepatitis C virus antibodies among blood donors in north-eastern Poland. Hepatol Res. 2005;33(3):206-10.

25. Soriano V, Mocroft A, Rockstroh J, Ledergerber B, Knysz B, Chaplinskas S, et al. Spontaneous viral clearance, viral load, and genotype distribution of hepatitis C virus (HCV) in HIV-infected patients with anti-HCV antibodies in Europe. J Infect Dis. 2008;198(9):1337-44

26. Arain A, Robaeys G, Stover H. Hepatitis C in European prisons: a call for an evidence-informed response. BMC Infect Dis. 2014;14 Suppl 6:S17.
27. Semaille C, Le Strat Y, Chiron E, Chemlal K, Valantin MA, Serre P, et al. Prevalence of human immunodeficiency virus and hepatitis $C$ virus among French prison inmates in 2010: a challenge for public health policy. Euro Surveill. 2013;18(28).

28. Saiz de la Hoya P, Marco A, Garcia-Guerrero J, Rivera A, Prevalhep study G. Hepatitis C and B prevalence in Spanish prisons. Eur Clin Microbiol Infect Dis. 2011;30(7):857-62.

29. Marco A, Gallego C, Cayla JA. Incidence of hepatitis C infection among prisoners by routine laboratory values during a 20-year period. PLoS One. 2014;9(2):e90560.

30. Treso B, Barcsay E, Tarjan A, Horvath G, Dencs A, Hettmann A, et al. Prevalence and correlates of HCV, HVB, and HIV infection among prison inmates and staff, Hungary. J Urban Health. 2012;89(1):108-16.

31. Mohd Hanafiah K, Groeger J, Flaxman AD, Wiersma ST. Globa epidemiology of hepatitis C virus infection: new estimates of age-specific antibody to HCV seroprevalence. Hepatology. 2013;57(4):1333-42.

32. Martinez-Rebollar M, Mallolas J, Perez I, Gonzalez-Cordon A, Lonca M, Torres B, et al. [Acute outbreak of hepatitis C in human immunodeficiency virus-infected patients]. Enferm Infecc Microbiol Clin. 2015;33(1):3-8.

33. Flisiak R, Halota W, Horban A, Juszczyk J, Pawlowska M, Simon K. Prevalence and risk factors of HCV infection in Poland. EurJ Gastroenterol Hepatol. 2011;23(12):1213-7.

34. Wandeler G, Gsponer T, Bregenzer A, Gunthard HF, Clerc O, Calmy $A$, et al. Hepatitis C virus infections in the Swiss HIV Cohort Study: a rapidly evolving epidemic. Clin Infect Dis. 2012;55(10):1408-16.

35. Cacoub P, Dabis F, Costagliola D, Almeida K, Lert F, Piroth L, et al. Burden of HIV and hepatitis C co-infection: the changing epidemiology of hepatitis C in HIV-infected patients in France. Liver Int. 2015;35(1):65-70.

36. Guriev V, Spinu C, Sajen O, Spinu I, Popovici S. Viral hepatitis B, $\mathrm{C}$ and HIV coinfection: Evaluation of some immunological and epidemiological aspects. HIV \& AIDS Review. 2014;13(2):46-9.

37. Berenguer J, Alejos B, Hernando V, Viciana P, Salavert M, Santos $\mathrm{I}$, et al. Trends in mortality according to hepatitis $\mathrm{C}$ virus serostatus in the era of combination antiretroviral therapy. AIDS. 2012;26(17):2241-6.

38. Hernando V, Alejos B, Monge S, Berenguer J, Anta L, Vinuesa D, et al. All-cause mortality in the cohorts of the Spanish AIDS Research Network (RIS) compared with the general population: 1997-2010. BMC Infect Dis. 2013;13:382. 